\title{
A Brief Analysis on the Development Direction of Dancing Teaching Gamification in Preschool Education
}

\author{
Xinyuan Lyu ${ }^{1, a}$ \\ ${ }^{1}$ Education Studies, School of Education, College of Social Sciences, University of Glasgow, St Andrew's Building, 11 \\ Eldon Street, Glasgow, G3 6NH, UK \\ ${ }^{a} 664614807 @ q q . c o m$
}

\begin{abstract}
Children's dance education has gradually become popular, but the existing teaching and training system is not suitable for children's physical and psychological development. Therefore, in this research, the author proposes to reform the existing children's dance teaching by gamification, explore in depth what kind of dance education is suitable for children's development, and analyze in detail the direction of activities suitable for children of each age group. The researcher chose the literature review method, analyzed the educational guidelines issued by the state, and did many kinds of research on the mind or body of young children. It specifically answered the reasons for the gamification of dance education and the training direction teachers should pay attention to in each age group. According to the results of the researcher's analysis of the literature, the gamification of dance is more in line with the development direction of China's early childhood education, and it is also more conducive to children's interest in dance and happily learning dance. Teachers should not have strict requirements for children aged 3-4. Knowing the Rhythm of music and cultivating an interest in dance is the focus of this stage. Children aged 4-5 have improved coordination and cognition, which can gradually cultivate their control of hands and feet and music perception. The 5-6 years old children are approaching maturity physically and mentally, and they can adequately join in flexibility exercises and pay attention to cultivating rule awareness. For children in the preschool education period, dance education should focus on cultivating interest and perception. The teacher needs to let the children like dancing instead of blindly emphasizing the standardization of movements and the improvement of skills.
\end{abstract}

Keywords: Dance teaching, early childhood education, teachers, gamification, preschool education

\section{INTRODUCTION}

With the continuous development of society and the continuous enrichment of material life in China, more and more parents and teachers are aware of the importance of art education. Joe's findings indicate that allowing preschool children to participate in art classes will help their emotional development [1]. Dance is an essential part of art education. Gabriela's research proves that dance courses can improve children and adolescents' health and metabolic adaptability and are beneficial to the physical development of children and adolescents [2]. Therefore, more and more parents realize the importance of art education for children and choose to let their children receive dance education during their early childhood. Early childhood education institutions have also begun to introduce dance education. However, the development of this phenomenon has brought a more severe problem. The traditional dance training system, such as basic skills training, technical skills training, and finished dance learning, is unsuitable for children's physical and psychological acceptance. Firstly, in the preschool education period, children's bones and muscles are not fully developed, they cannot control and coordinate, they cannot control their limbs to perform dance movements accurately, and they have not formed abstract thinking to understand the emotional connection between music and dance movements. Secondly, traditional dance training is relatively dull and accompanied by some pain, and it will make children lose interest in dance and even hate it. Therefore, allowing young children to receive the training of the traditional system will not only be beneficial to young children's development but will also bring significant damage to their biology and psychology. Therefore, how to carry out dance education for children is an important issue that many dance teachers are facing, which is worthy of research and discussion. In recent years, the mode of 
gamification teaching in early childhood education has been constantly mentioned. Researchers have conducted analysis and research on some early childhood education and children's psychology and believe that gamification of dance teaching in early childhood education is a direction worth trying. Based on early childhood education and dance education, this article mainly uses literature review methods to analyze social forms and children's psychology, explore the reasons for the glamorization of dance in early childhood education, and how teachers should teach at different ages.

\section{REASONS FOR GAMIFICATION OF DANCE IN EARLY CHILDHOOD EDUCATION}

More and more early childhood education institutions in China have introduced or started to introduce dance education as a formal course or extracurricular activity. Ren Lixin proposed in his research that participating in extracurricular activities is beneficial to the development of Chinese preschool children's cognitive, language, and emergency reading and writing skills, but it is necessary to critically reflect the impact of on allowing organized off-campus activities children to participate from such an early age [3]. Hence, under the premise that the traditional dance education system is not suitable for children's dance education, how to make the dance contribute to the development of children, instead of becoming a weapon to harm children is every kindergarten educator and dance teacher needs to think seriously.

From the perspective of social policy, following the continuous development of quality education in China, "The Action Plan for the Promotion of Education in the 21st Century" [4] proposes that the implementation of quality education should start from the early childhood stage and use scientific methods to stimulate and develop children's intelligence. In 2001, Ministry of Education of the People's Republic of China pointed out in the "Guidelines for Kindergarten Education (Trial)" that in children's art education, it is necessary to avoid only focusing on performance skills or the results of artistic activities while ignoring children's emotional experience in the process of activities and attitude tendencies [5]. In the National Medium and Long-term Education Reform and Development Plan Outline (2010-2020), it is emphasized that education is of great significance to children's physical and mental health [6]. Therefore, letting children learn to dance happily in games has become an inevitable development direction of children's dance education.

From the perspective of children's acceptance, interest is the best teacher for children, and learning through play allows children to experience the charm of art better. Dan Zhao believes that children's dance games conform to the characteristics of children's development, effectively improving teaching efficiency and teaching effects and promoting the physical and mental health of children [7]. Ping Liao and Wei Zhou also believe that "scientific, healthy and happy" dance education should be promoted to realize the core value of children's dance education [8]. Dance should be happy. In dance education, letting children feel the joy of dance is the foundation of children's dance education. Therefore, making children feel happy in the dance classroom is a question that every dance teacher needs to consider. It's also the reason why dance becomes a game.

From the perspective of social practice, Yaqin Kong observed the dance teaching of 200 children of different ages in two kindergartens in Lixia District and Shizhong District of Jinan in his master's thesis "Research on the game of children's dance teaching" [9]. Kong believes that children often show emotions of boredom and fear under the traditional dance teaching mode, which is detrimental to children's development and dance learning. Moreover, gamified dance teaching can make children have a relaxed and happy learning atmosphere, allow children's muscles to participate in activities actively, and improve children's learning dance effectiveness.

\section{PRACTICE FOR CHILDREN'S TEACHERS OF DIFFERENT AGE GROUPS}

Children in preschool education are generally 3-6 years old. Although the age span is not large, children's physical and psychological changes during this period are incredibly rapid, and their physical and psychological states will be different every year. Therefore, for children of every age, teachers should also change the content and methods of dance teaching. This study is divided into three stages: 3-4 years old, 4-5 years old and 5-6 years old. Through comparing Xuehong Fang and Haiming Zhu's "Kindergarten Sports Game Activity Design" [10], Qing Chen and Mengdi Zhang's "Children's Dance Choreography and Practical Tutorial" [11], Li Dong's "Kindergarten Dance Teaching Activity Design and Guidance" [12], and the teaching tasks for grades one to three of the Syllabus for graded examination on Chinese dance, the author analyzed the physical and mental development characteristics of each child and the degree of acceptance of dance, and proposes appropriate activity design directions and problems that need attention.

\subsection{3-4 years old}

Children aged 3-4 have minimal dance cognition and physical control. From the physical point of view, Fang believes that children's balance can be improved by 4-5 times from the age of 6 years old, and they must be practiced after the age of 3 , but their muscle endurance and control are poor, and the ability to jump continuously on one foot is not good. Chen proposed that young 
children can master large body movements and small parts of fine movements at this stage. Dong also put forward this point but believes that the overall level of children's basic movements at this stage is relatively low, and they cannot complete the movements with confidence. From a psychological point of view, Dong believes that children in this period are in the formation stage of concrete thinking, and abstract thinking has not sprouted. Chen believes that children can understand simple instructions from adults in this period, but their attention span is not long. The two pointed out that children at this stage showed a strong interest in imitation. In Sun's Syllabus for graded examination on Chinese dance: grade 1, it is pointed out that the teaching task at this stage should be to understand the essential parts of the body, to understand the left and right, to understand the rhythm of music, and to cultivate children's love for dance [13]. Therefore, the author suggested that the design of dance games at this stage should focus on imitating and understanding the body, focusing on training children's balance ability and sense of Rhythm, with the primary purpose of cultivating children's interest and reducing the requirements for movement standards. The selected music should also have a precise rhythm and simple melody to reduce the interference of music on children's attention and make it easier for children to find the Rhythm of the music. At the same time, Dong suggested in his research that the activities at this stage should be taught while playing. Teachers need simple language so that children can understand the rules of the game. The duration of the game is controlled within 5-10 minutes.

\subsection{4-5 years old}

Children aged 4-5 have improved coordination and cognition. From the physical aspect, Fang believes that children's balance and muscle endurance develop rapidly at this stage, but the coordination is still insufficient. Chen believes that children's physical strength is enhanced during this period, their energy is energetic, their movements are more flexible, and they can do some coherent movements. Dong further proposed that during this period of small muscle development for young children, proper exercise should be given. From a psychological point of view, Chen believes that children of this age have strengthened their perception of music, but the accuracy of their actions needs to be improved. At the same time, children's awareness of rules begins to sprout, and their imagination and thinking further develop. They can play their imagination with the rhythm. Dong believes that children aged 4-5 years are still in the stage of unintentional attention, but intentional attention is also constantly developing, showing a trend of transformation between the two parties. In Sun's "Syllabus for graded examination on Chinese dance: grade 2, it is pointed out that the teaching task at this stage should be to understand the basic orientation of the room, and initially achieve neck standing, back straight, straight legs, and feet stretched, and cultivate children's dance habits and maintain a happy attitude [14]. Therefore, the author suggests that during this period, teachers can focus on cultivating children's control over the hands and feet and the perception of music. To enhance children's initiative in music, teachers can try to give a piece of simple music for children and guide them to express their imagination based on the music. In terms of music selection, teachers can choose music with strong emotions to cultivate children's perception and creativity. During this period, children's attention has improved, and the duration of the activity can be controlled within 10-15 minutes. During the activity, the children can be adequately reminded to abide by the rules and cultivate their awareness.

\subsection{5-6 years old}

The abilities of children aged 5-6 are beginning to approach those required for traditional dance training. From the physical aspect, Fang believes that children's balance during this period has been well developed, and coordination has also been greatly improved. Chen believes that at this stage, children can act independently and control their bodies. Dong believes that during this period, the strength of the muscles and joints of children has increased, they have specific control over balance and center of gravity, and they can accept some complex dance activities. From the psychological aspect, Chen believes that children at this stage have a strong desire to create, and they have already possessed musical awareness and musical perception capabilities. Dong believes that children's abstract thinking began to sprout during this period, and they can concentrate on learning simple abstract dances. Children can also feel the specific musical details and change their speed of action according to the changes in the music. In Sun's Syllabus for graded examination on Chinese dance: grade 3, it is pointed out that the teaching task at this stage should be to understand the essential position of oneself, find the rhythm of the music, and cultivate a sense of self-entertainment in dance [15]. Therefore, at this stage, the author recommends that teachers pay attention to children's rules and actions when designing dance activities, add game props appropriately, and set up some games to cultivate children's expressiveness and Rhythm. During this period, a variety of music choices also provided teachers with a variety of activities. Since the children's body is approaching maturity, teachers can also add some flexibility exercises and simple technical skills learning. However, the safety of the children should be the priority, not rushing, and the duration of the activity is about 20 minutes.

\section{CONCLUSION}

In this article, the author analyzes the existing literature and believes that gamification of dance 
education is suitable for children to accept. The author combines the children's physical and psychological state to analyze the teaching focus of each age group, focusing on cultivating children's interest and focusing on balance, rhythm, hand and foot control, and music perception, to simple flexibility exercises and creativity, to cultivate children's interest in dance and improve their physical and mental abilities. As a result, children can be getting the professional dance training at the right age and in a good state. However, this research only analyzes the activities suitable for each age group and gives some directional suggestions and does not design specific activities that are indeed feasible. This can be explored in subsequent research.

\section{REFERENCES}

[1] Shubei Qiao, Olga Tapalova, Liliya Nasyrova c Ilona Tarasova, Daria Kozlovskaya. Role of art programs in young children's social-emotional learning. Thinking Skills and Creativity, 41 (2021) 100858.

[2] Gabriela Cristina dos Santos, J'essica do Nascimento Queiroz, A'lvaro Reischak-Oliveira, Josianne Rodrigues-Krause. Effects of dancing on physical activity levels of children and adolescents: a systematic review. Complementary Therapies in Medicine 56 (2021) 102586.

[3] Lixin Ren, Traci Shizu Kutaka, Pavel Chernyavskiy, Jieqiong Fan, Xuan Li. The linear and nonlinear effects of organized extracurricular activities on $\mathrm{T}$ Chinese Preschoolers' development. Contemporary Educational Psychology, 2020, 60: 101845.

[4] The 15th National Congress of the Communist Party of China.The Action Plan for the Promotion of Education in the 21st Century. 1998.

[5] Ministry of Education of the People's Republic of China. Guidelines for Kindergarten Education (Trial). 2001.

[6] State Council Executive Meeting. National Medium and Long-term Education Reform and Development Plan Outline. 2010-2020.

[7] Dan Zhao. Research on children's dance game teaching practice. Dance Fashion. CNKI:SUN:SAWU.0.2021-09-044.

[8] Ping Liao and Wei Zhou. Reflections on the value orientation of dance education for preschool children in China. Sichuan Drama. CNKI:SUN:SCXJ.0.2013-08-047.

[9] Yaqin Kong. Research on the game of children's dance teaching. 2016.
[10] Xuehong Fang and Haiming Zhu. Kindergarten Sports Game Activity Design. Sichuan University Press. 2013, 25-37.

[11] Qing Chen and Mengdi Zhang. Children's Dance Choreography and Practical Tutorial. Chongqing University Press, 90-401.

[12] Li Dong. Kindergarten Dance Teaching Activity Design and Guidance. Peking University Press, 179-232.

[13] Edited by Beijing Dance Academy, Edutor in Chief Sun Guangyan. Syllabus for graded examination on Chinese dance: grade 1 (for per-school children). People's Music Publishing House, 2020, 6.

[14] Edited by Beijing Dance Academy, Edutor in Chief Sun Guangyan. Syllabus for graded examination on Chinese dance: grade 2 (for per-school children). People's Music Publishing House, 2020, 6.

[15] Edited by Beijing Dance Academy, Edutor in Chief Sun Guangyan. Syllabus for graded examination on Chinese dance: grade 3 (for per-school children). People's Music Publishing House, 2000, 6. 